\title{
INTELIGÊNCIA EMOCIONAL E COMUNICAÇÃO INTERPESSOAL DAS PESSOAS COM DEFICIÊNCIA INSERIDASS NO MERCADO DE TRABALHO
}

\author{
Marta Alexandra Gonçalves Nogueira ${ }^{1}$ e Célia Maria Adão de Oliveira Aguiar de Sousa² \\ ${ }^{1}$ ESECS-IPLeiria, Portugal. marta.nogueira@ipleiria.pt \\ ${ }^{2}$ ESECS, CRID, CICS.NOVA. IPLeiria, Portugal. celia.sousa@ipleiria.pt
}

\begin{abstract}
Resumo. O presente artigo versa sobre a inteligência emocional, a comunicação interpessoal e a integração de pessoas com deficiência no mercado de trabalho. As pessoas com deficiência enfrentam ainda o preconceito e a discriminação, no que respeita à sua integração no mercado de trabalho. A integração neste meio é vista cada vez mais como um elemento determinante para a inclusão social, a independência económica e a concretização pessoal. Neste âmbito, devido à escassez de estudos existentes e perante a desvantagem vivenciada pelas pessoas com deficiência na inclusão ao mercado de trabalho, procurámos explorar e perceber como é que o mundo organizacional acolhe estes trabalhadores, quais as emoções sentidas e como as gerem no decorrer da jornada de trabalho e, saber ainda como se processa a comunicação neste contexto. A metodologia adotada é de natureza qualitativa e design de estudo de caso, combinando diferentes técnicas e instrumentos, que permitem a obtenção de dados de diferentes tipos e a hipótese de cruzamento e contraste de informação, a saber: entrevistas e questionários.
\end{abstract}

Palavras-chave: Pessoas com deficiência; Inclusão; Inteligência Emocional; Comunicação Interpessoal; Mercado de Trabalho.

\section{EMOTIONAL INTELLIGENCE AND INTERPERSONAL COMMUNICATION OF PEOPLE WITH DISABILITIES IN THE LABOR MARKET}

\begin{abstract}
This article deals with emotional intelligence, interpersonal communication and the integration of people with disabilities in the labour market. People with disabilities still face prejudice and discrimination in terms of their integration into the labour market. Integration in this environment is increasingly seen as a determining element for social inclusion, economic independence and personal fulfilment. In this context, due to the scarcity of existing studies and in view of the disadvantage experienced by people with disabilities in inclusion in the labour market, we tried to explore and understand how the organizational world welcomes these workers, what emotions are felt and how they manage them during the working hours and, knowing how to process communication in this context. The methodology adopted is of a qualitative nature and case study design, combining different techniques and instruments, which allow obtaining data of different types and the hypothesis of crossing and contrasting information, namely: interviews and questionnaires.
\end{abstract}

Keywords: Disabled People; Inclusion; Emotional Intelligence; Interpersonal Comunication; Labour Market.

\section{INTRODUÇÃO}

A inclusão social tem ocupado um lugar de destaque na nossa sociedade, contribuindo para fomentar a inclusão dos segmentos em vulnerabilidade social. Desta forma, a sociedade deve conceber conjunturas que estimulem a transformação da mentalidade das pessoas que dela fazem parte, visando a abertura às diferenças de forma a que todas as pessoas consigam viver plenamente (Borba \& Lima, 2011). Conceber conjunturas demanda a 
existência de sistemas e de políticas de apoio a vários níveis, nomeadamente: informação, assistência pessoal, transportes, acessibilidades, emprego, educação, formação, subsídios quando aplicáveis e a defesa plena de direitos (Crespo, 2013).

Um dos pilares da inclusão social é a integração da pessoa com deficiência no mercado de trabalho (Calhoa, 2017). Para a pessoa com deficiência a inclusão no mercado de trabalho significa que há uma inclusão na sociedade, a oportunidade de desenvolver uma carreira profissional e uma identidade de cariz social, ou seja, é uma forma de afirmação social através da qual procuram ver reconhecida a sua dimensão de cidadãos (Gonçalves \& Nogueira, 2012).

Neste pressuposto, o objetivo geral da nossa investigação centra-se em perceber como é que o mercado de trabalho integra as pessoas com deficiência, perceber quais as emoções por si sentidas e como as gerem ao longo da jornada de trabalho, e ainda saber como se processa a comunicação no meio laboral. Tal suscitou a definição dos seguintes objetivos específicos: conhecer o grau de consciência que os trabalhadores com deficiência têm das suas emoções nas interações diárias no seu local de trabalho; analisar as interações comunicativas das pessoas com deficiência em contexto laboral; e, por fim, verificar em que medida a Convenção sobre os Direitos das Pessoas com Deficiência melhorou o processo de inclusão.

Nesta perspetiva, importa ressalvar que este artigo relata o desenvolvimento de uma investigação de doutoramento que ainda se encontra em curso, e que tem como finalidade contribuir para o reconhecimento unânime do direito ao trabalho, visto que o emprego assume uma importância fulcral no processo de inclusão social e de emancipação económica das pessoas com deficiência (Gonçalves \& Nogueira, 2012).

\section{FUNDAMENTAÇÃO TEÓRICA}

Vivemos numa sociedade constituída por diversas pessoas, com diferentes características, mas com uma ininterrupta indagação pela "igualdade", por uma sociedade análoga em que todas as pessoas detenham direitos iguais e consigam fruir das mesmas regalias. Nesta indagação por reconhecimento destacamos a luta das pessoas com deficiência pela inclusão no meio social e no mundo do trabalho (Pereira 2015). 
A pessoa com deficiência é inteiramente capaz de exercer uma função dentro de uma organização, independentemente da sua deficiência, conseguindo alcançar sucesso profissional como qualquer outra pessoa. No entanto, o sucesso profissional destes e de todos os cidadãos não depende unicamente das aptidões e competências técnicas, mas da autoconfiança, autonomia e facilidade relacional, bem como da capacidade para dominar as emoções e as competências comunicacionais (Arândiga, 2009).

As pessoas no ambiente laboral podem intencionalmente criar meios de interação, onde as emoções geradas sejam motivadoras de ação, autonomia e sentimento de competência, essenciais para o trabalhador com deficiência sair da posição vulnerável e afirmar-se, isto é, conquistar a condição e capacidade de participação, a inclusão social e o pleno exercício da sua cidadania ((Dantas, Rabelo e Marinho, 2016).

As emoções edificam o mundo subjetivo dos trabalhadores com algum tipo de deficiência, pelo que a partir da compreensão das mesmas, é possível auxiliá-los a desenvolver as suas potencialidades, reconhecendo-os na sua íntegra (Alvim e Rodrigues, 2015). As emoções podem comunicar aos outros o que sentimos e influenciar no que os demais sentem (Bisquera, Pérez \& Garcia, 2015).

Neste seguimento pode-se afirmar que a comunicação não é somente dar a conhecer uma informação, mas sim uma constante troca de estados emocionais entre os interlocutores, que pode ter repercussões na organização (Alves e Pinto, 2014). Através dela, é possível estabelecer inter-relações de cariz formal e emotivo que proporcionem a fidelização gradual dos trabalhadores à organização (Curvello, 2008). Desta forma, a comunicação deve fluir por toda a estrutura organizacional, abrangendo todos os trabalhadores, pois dela depende o bom funcionamento e o bom relacionamento dentro da organização. O trabalhador com deficiência carece de auxílio na sua integração, pelo que é imprescindível que a comunicação interna transmita ao trabalhador em questão e aos seus colegas, sentimentos positivos em relação à organização, fazendo-os compreender que a inclusão depende também das ações de cada um (Pereira, 2015).

As organizações são construções sociais, nas quais os trabalhadores com deficiência pretendem ter acesso às mesmas informações e oportunidades dos demais trabalhadores. Eles incutem uma nova dinâmica no ambiente organizacional, fazendo com que demais trabalhadores saiam da sua zona de conforto e passem a conviver em harmonia num espaço que respeita as diferenças, limitações e rompe as barreiras do preconceito. Quando 
a organização assume a responsabilidade de levar o processo comunicacional de maneira eficaz a todos os seus trabalhadores, incluindo os trabalhadores com deficiência, ela está a assumir o seu papel de transformadora da sociedade (Marchiori, 2010).

Logo, é premente que as entidades empregadoras compreendam que estão perante uma força de trabalho e não perante uma pessoa incapacitada

\section{METODOLOGIA}

A nossa investigação está a ser realizado no Grupo Auchan Portugal, que assume um exemplo de boas práticas na área do recrutamento e integração de pessoas com deficiência.

Os atores da nossa investigação são os trabalhadores com deficiência, que interagem num cenário concreto, o local de trabalho. A nossa amostra é constituída por 50 trabalhadores com deficiência, que exercem as suas funções nos hipermercados do Grupo Auchan de Norte a Sul do país e que se distribuem por dois grupos: um grupo cuja integração no mercado de trabalho foi realizada com recursos às Instituições parceiras $(31,67 \%)$ e um grupo cuja integração no mercado de trabalho foi realizada através de candidatura própria (68,33\%). Do total, 30 são do sexo masculino e 20 do sexo feminino, com idades compreendidas entre os 19 e os 64 anos $(M=41,55, D P=8,754)$.

De acordo com os objetivos delineados para a presente investigação e, pretendendo uma aproximação profunda a uma realidade circunscrita, optámos pela utilização do método do estudo de caso, que se adscreve na investigação qualitativa e se apresenta como um método que nos divulga maiores potencialidades, pois integra o que os participantes dizem, as suas experiências, atitudes, crenças, pensamentos e reflexões (Lopes, 2011).

Numa investigação de cariz qualitativo pode-se recorrer à triangulação com dados quantitativos, ou seja, dualismo entre metodologias - qualitativo versus quantitativo (Faria \& Vieira, 2016). A nossa conduta de recolha de dados foca-se na utilização de diversas técnicas e instrumentos, que permitam a obtenção de dados de diferentes tipos e proporcionem a hipótese de cruzamento e contraste da informação, a saber: entrevista aos trabalhadores com deficiência; entrevista ao responsável da entidade empregadora; questionário online aos responsáveis de mercado; questionário online aos colegas de 
trabalho dos trabalhadores com deficiência (colegas de trabalho "diretos") e entrevista ao poder político responsável (Secretária de Estado da Inclusão das Pessoas com deficiência).

As entrevistas aos atores da nossa investigação, trabalhadores com deficiência, foram realizadas presencialmente em cada hipermercado, mediante agendamento prévio com o responsável de mercado e com recurso a registo digital, com o consentimento informado de cada trabalhador. Para a realização da entrevista foi elaborado um guião, partindo das problemáticas relacionadas com os objetivos da nossa investigação, sendo que para cada objetivo foram delineadas três ou mais questões encadeadas de forma sequencial, saber: 1. objetivo são questões relativas às emoções (mais comuns) sentidas num dia de trabalho: "Qual o principal sentimento/emoção que caracteriza o seu dia-a-dia no trabalho?"; para o 2. objetivo estabelecem-se questões sobre a comunicação interpessoal em contexto laboral: "A comunicação organizacional satisfaz as suas necessidades e expetativas?"; para o $3 .^{\circ}$ objetivo são estabelecidas questões, no que concerne à integração ao local de trabalho: "De que forma "ingressou" no seu atual posto de trabalho? Sente-se integrado?". A entrevista é semiestruturada sendo justificados os motivos desta opção (acesso a grande quantidade de informação e esclarecimento dessa informação).

Os questionários foram produzidos no "Google Forms", e encaminhados para os diretores de loja através de correio eletrónico, com a finalidade de serem respondidos pelos colegas de trabalho diretos dos trabalhadores com deficiência, bem como pelos responsáveis de mercado. O questionário tem como objetivo recolher informação rápida e clara sobre as opiniões destes trabalhadores, pelo que procurámos elaborar perguntas claras, concretas e concisas que nos permitissem obter dados puros.

A nossa investigação encontra-se na fase de tratamento dos dados recolhidos. Esta fase revela três momentos primordiais: a descrição, que corresponde à escrita de textos decorrentes dos dados registados pelo investigador; a análise que é o procedimento de organização de dados, e onde se reconhecem os aspetos e fatores; e a interpretação diz respeito ao processo de obtenção de interpretações e inferências a partir dos dados obtidos (Vale, 2004). Tomando como referência estes três momentos e, adequando-os à nossa investigação, podemos referir que a descrição corresponde à escrita de textos resultantes das entrevistas realizadas aos trabalhadores com deficiência, a análise corresponde ao resumo e/ou estruturação das notas de campo e a interpretação dos resultados será obtida através de resumos finais fundamentados na análise dos dados. 
O tratamento dos dados recolhidos inclui a análise do conteúdo a partir de categorias de análise pré-definidas, decorrentes da revisão da literatura e dos objetivos da investigação. Os questionários aplicados são sujeitos a análise estatística e análise de conteúdo. As entrevistas são sujeitas a análise de conteúdo.

\section{CONCLUSÕES PROVISÓRIAS}

A inclusão das pessoas com deficiência ao mercado de trabalho é fulcral para a construção de uma sociedade solidária e justa, ou seja, uma sociedade que proporcione igualdade de oportunidade a todos os cidadãos (Malhado, 2013). É premente combater o estigma associado a esta população, demonstrando que estas pessoas têm capacidades para desenvolver determinadas atividades, desde que o posto de trabalho que ocupam, ou possam vir a ocupar, seja adequado às suas competências (Figueira, 2012).

O presente estudo, é um estudo qualitativo com benefícios intrínsecos, contribuindo para uma maior perceção das dinâmicas de inclusão e exclusão das pessoas com deficiência que estão incluídas no mercado de trabalho, assegurando sobretudo uma maior aproximação ao público-alvo e a compreensão das experiências vividas, bem como das suas perceções e sentimentos.

$\mathrm{Na}$ amostra conseguida existe uma grande variedade de idades, deficiências e funções desempenhadas. Acresce que os indivíduos que integram a amostra encontram-se dispersos por todo o território nacional, não se circunscrevendo o estudo a uma área limitada. Todos os entrevistados revelaram que a inclusão no mercado de trabalho é essencial para a sua valorização pessoal.

Ao concebermos oportunidades de emprego para as pessoas com deficiência, estaremos a construir uma sociedade mais inclusiva, que valoriza, potencia e dá relevância às competências e ao capital humano destas pessoas.

\section{REFERÊNCIAS}

Alves, A. \& Pinto, J. (2014). A Importância da Perceção Comunicacional nas Organizações. Universidade Autónoma de Lisboa: Lisboa.

Alvim, J. \& Rodrigues, V. (2015). A relevância dos aspetos emocionais do deficiente físico para a inclusão no ambiente de trabalho. Universidade do Oeste Paulista: Brasil.

Arándiga, A. (2009). La inteligência emocional de los padres y de los hijos. Madrid: Ediciones Pirámide. Bisquerra, R., Pérez, J., García, E. (2015). Inteligencia emocional en educación. Editorial Síntesis, Madrid. 
Borba, A. \& Lima, H. (2011). Exclusão e inclusão social nas sociedades modernas: um olhar sobre a situação em Portugal e na União Europeia. Serviço Social \& Sociedade, 106, 219-240.

Calhoa, V. (2017). Inclusão Social de Jovens com Deficiência e Incapacidade: o Centro de Reabilitação Profissional como Mediador. Dissertação de Mestrado. Instituto Politécnico de Leiria: Leiria.

Crespo, A. (2013). Deficiência Mental Moderada e Empowerment: Um estudo de caso na CERCIGuarda. Dissertação de Mestrado não editada. Universidade da Beira Interior: Covilhã.

Curvello, J. (2008, setembro). A dimensão interna da comunicação pública. In Intercom - Sociedade Brasileira de Estudos Interdisciplinares da Comunicação. XXXI Congresso Brasileiro de Ciências da Comunicação. Trabalho apresentado no NP Relações Públicas e Comunicação Organizacional do VIII Nupecom Encontro dos Núcleos de Pesquisa em Comunicação, Natal, Brasil. Retrieved from http://www.intercom.org.br/papers/nacionais/2008/ resumos/R3-2065-1.pdf .

Dantas, T., Rabelo, F., \& Marinho, F. (2016). Educação Emocional: Um Novo Paradigma para a Inclusão e o Empoderamento das Pessoas com Deficiência. Universidade Federal da Paraíba: Brasil.

Figueira, D. (2012). Acesso ao Mercado de Trabalho: o caso das pessoas com Deficiência Mental. Dissertação de Mestrado não editada. Universidade da Beira Interior: Covilhã.

Gonçalves, J. (coord), \& Nogueira, J. (2012). O Emprego das Pessoas com Deficiências ou Incapacidade - Uma abordagem pela igualdade de oportunidades. Lisboa: MSSS - Gabinete de estratégia e planeamento.

Malhado, C. (2013). A deficiência mental e o mundo laboral: representações e vivências. Dissertação de Mestrado não editada. Instituto Politécnico de Bragança: Bragança.

Marchiori, M. (2010). Comunicação e Organização: Reflexões, Processos e Práticas. São Caetano: Difusão Editora.

Pereira, B. (2015). As relações públicas e as estratégias para a inclusão de deficientes no ambiente organizacional. Dissertação de Mestrado não editada. Universidade Federal do Pampa: São Borja.

Vale, I. (2004). Algumas Notas Sobre Investigação Qualitativa em Educação Matemática. O Estudo de Caso. Revista da Escola Superior de Educação de Viana do Castelo. Vol.5, 171-202. 